\title{
Quem habita o corpo trans?
}

\author{
Patricia Porchat ${ }^{1}$ id 0000-0002-6192-0682 \\ Maria Caroline Ofsiany ${ }^{2}$ (iD 0000-0002-7038-122X
}

'Universidade Estadual Paulista, Faculdade de Ciências, Departamento de Psicologia, Bauru, SP, Brasil. 17033-360

${ }^{2}$ Universidade Estadual Paulista, Faculdade de Medicina, Programa Saúde do Adulto e do Idoso, Botucatu, SP, Brasil. 18618-687

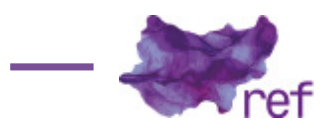

Resumo: Neste artigo são comparados os discursos produzidos pelo movimento transfeminista, pela medicina e pela psicanálise, buscando pontos de encontro e de divergência em relação à questão do corpo em pessoas trans. Realizamos uma revisão bibliográfica através da Análise de Conteúdo de Laurence Bardin. As categorias que se destacaram foram: saúde/doença (medicina), autonomia (movimento transfeminista) e subjetividade (psicanálise). Os três discursos, articulados através dessas categorias, tornaram evidente a existência de diferentes sentidos atribuídos ao corpo, a partir da produção de verdades de cada um. O diálogo, necessário quando se trata de intervenções corporais, reivindicação de direitos ou compreensão do eventual sofrimento, pode ou não ocorrer, a depender do regime discursivo em que o sentido ao corpo é atribuído.

Palavras-chave: Transexualidade; corpo; psicanálise; transfeminismo; transidentidades

Who Inhabitates a Trans Body?

Abstract: This article compares the discourses produced by the transfeminist movement, medicine and psychoanalysis, seeking points of encounter and divergence in relation to the question of the body in trans people. We conducted a literature review through Laurence Bardin's Content Analysis. The categories that stood out were health / illness (medicine), autonomy (transfeminist movement) and subjectivity (psychoanalysis). The three discourses, articulated through these categories, made evident the existence of different meanings attributed to the body, from the production of truths of each one. Dialogue, necessary when it comes to corporal interventions, claims of rights or understanding of possible suffering, may or may not occur depending on the discursive regime in which meaning to the body is attributed.

Keywords: Transsexuality; Body; Psychoanalysis; Transfeminism; Transidentities

\section{Introdução}

Neste artigo apresentamos os resultados de uma pesquisa em que se buscou identificar pontos de encontro e divergência na concepção de corpo na transexualidade em três áreas de conhecimento distintas: transfeminismo, medicina e psicanálise. Trata-se de saberes que possuem algumas interdependências quando examinada a questão da modificação corporal que pressupõe intervenções cirúrgicas sobre o corpo das pessoas trans. Por exemplo, no Brasil, para a realização de uma cirurgia de redesignação sexual no SUS, é necessário seguir um rígido protocolo que envolve um diagnóstico médico de Transexualismo/Disforia de gênero, além de dois anos de psicoterapia obrigatória. Nesse sentido, as pessoas que buscam a cirurgia estão submetidas a um suposto saber de profissionais da psicologia ${ }^{1}$ e da medicina. Para a cirurgia ser autorizada é

\footnotetext{
${ }^{1}$ Frequentemente, aquele ou aquela que exerce a função de psicólogo que fornece um laudo ou realiza acompanhamento psicoterápico é também um ou uma psicanalista ou se fundamenta na teoria psicanalítica que, desde a década de 60 , é a principal corrente teórica da psicologia a produzir um saber sobre essas questões.
} 
preciso que estes profissionais estejam de acordo. Fora do SUS, a psicanálise depende da medicina no que tange à decisão última de qualquer intervenção sobre o corpo de uma pessoa trans; em contrapartida, a medicina raras vezes se articula à psicanálise para suas decisões. Embora esses campos de conhecimento dependam um do outro, o corpo da pessoa trans, referenciado em cada discurso, é compreendido de forma distinta. $O$ transfeminismo defende a autonomia e o poder de decisão das pessoas trans para com seus próprios corpos; a medicina trata o corpo das pessoas trans como corpo doente e busca o "verdadeiro transexual" elegido aos seus próprios critérios, explicitados nas categorias diagnósticas relativas à transexualidade - seja no Manual Diagnóstico e Estatístico de Trantornos Mentais (DSM), seja no Código Internacional de Doenças (CID). Ao longo dos últimos anos, observa-se uma evolução no sentido da despatologização e no CID 11 , sendo que a transexualidade aparece como Incongruência de gênero no capítulo sobre Condições relativas à saúde sexual - em substituição à sua localização no capítulo de Transtornos mentais de identidade de gênero (CID 10). Todavia, essa alteração, que entrará em vigor apenas em 2022, continua sendo objeto de crítica por transfeministas, na medida em que se trata de uma categoria diagnóstica e não cultural (Jaqueline Gomes de JESUS, apud Neto LUCON, 2018). O termo incongruência, que sugere anomalia, equívoco (Viviane VERGUEIRO, apud LUCON, 2018), denuncia o pressuposto de que a congruência está do lado da cisgeneridade, nomenclatura para pessoas que não são transgêneras, usada como alternativa a termos considerados pejorativos, como mulher/homem "biológicos/verdadeiros" (Leila DUMARESC, 2016; Amara RODOVALHO, 2017).

Por último, a psicanálise entende o corpo, de modo geral, como corpo erógeno, constituído conjuntamente com a subjetividade. Ainda assim, não existe, na psicanálise, um consenso sobre a questão da intervenção sobre o corpo quando se trata de pessoas trans.

Para além de uma interdependência entre distintos saberes e práticas, no que concerne ao corpo de pessoas trans, é importante salientar a heterogeneidade discursiva que o constitui. Talvez este seja o ponto de tensão que melhor ilustra o desafio de se fazer este tipo de análise. A realidade material de um corpo que, em última instância, é apenas acessível através da linguagem, na medida em que é ela quem produz os sentidos que o descrevem, talvez só possa ser alcançada, enquanto objeto de pesquisa, se a própria discursividade estiver em pauta. Pode, efetivamente, algum discurso atingir uma verdade sobre o corpo trans? Ou será melhor dizermos que os diferentes discursos produzem diferentes 'verdades' sobre os corpos trans?

\section{Metodologia}

Num primeiro momento, adotamos como metodologia para a realização desta pesquisa a Análise de Conteúdo (Laurence BARDIN, 2011), entendida como um conjunto de técnicas metodológicas aplicadas a discursos variados. Busca-se investigar o escondido, o latente e o não aparente, retidos por qualquer mensagem (BARDIN, 201 1 , p. 9). Essa metodologia se organiza em três etapas: (1) a pré-análise, que consiste na escolha dos documentos que serão submetidos à análise, na formulação de hipóteses e de objetivos e na elaboração de indicadores que irão fundamentar a interpretação final; (2) a exploração do material, que seguirá aquilo que foi sistematizado na etapa de pré-análise; (3) o tratamento dos resultados e a interpretação, que dependerão da técnica de análise escolhida.

Dentre as variadas técnicas que a Análise de Conteúdo permite (categorial, enunciação, expressão, entre outras), consideramos que a análise categorial seria a que melhor possibilitaria a visualização das semelhanças e diferenças entre os discursos que pretendíamos analisar. Acreditávamos ser possível comparar os saberes produzidos pelo discurso médico, pelo movimento transfeminista, e pela psicanálise, no tocante à questão do corpo das pessoas trans. A análise categorial consiste na categorização de elementos de um discurso, sendo a categoria uma composição de um grupo de elementos em função de características comuns, sob um título genérico. A categorização é realizada a partir da escolha de um critério (semântico, sintático, léxico, entre outros). Escolhemos o critério semântico, que consiste na elaboração de categorias temáticas (BARDIN, 201 1, p. 117). Definido o critério, escolhe-se o processo de categorização: o procedimento 'caixa', que é quando se estabelece categorias de antemão e agrupa-se os elementos encontrados; e o procedimento 'milha', que igualmente agrupa elementos, mas o título conceitual de cada categoria é escolhido somente no final da operação (p. 119). Em nossa análise, utilizamos ambos os processos. O levantamento bibliográfico foi realizado através de buscas em livros, dissertações, teses em artigos publicados após a resolução n 1482/97 do Conselho Federal de Medicina (1997). Essa resolução² inaugurou a possibilidade de realização da cirurgia de redesignação sexual no Brasil em hospitais públicos e/ou universitários ligados à

\footnotetext{
${ }^{2}$ Em 2002, é publicada a segunda Resolução CFM n 1652/2002 revogando a primeira. Amplia-se a possibilidade de cirurgia de adequação do fenótipo masculino para o feminino para qualquer hospital público ou privado, mas mantém-se as do fenótipo feminino para o masculino em hospitais públicos ligados à pesquisa. Atualmente é a Resolução CFM n 1955/2010 que vigora. Nela, a cirurgia do fenótipo feminino para o masculino passa a ser autorizada em qualquer hospital público ou privado, embora continue sendo a título experimental.
} 
pesquisa. A revisão bibliográfica inicial resultou em três categorias prévias, uma para cada discurso, que foram: corpo-autonomia, para o movimento transfeminista; corpo-saúde/doença, para o discurso médico e corpo-subjetividade, para a psicanálise. Ao longo do trabalho colocamos em questão: o que é autonomia (transfeminismo) para a medicina e a psicanálise; o que é saúde/ doença (medicina) para o transfeminismo e a psicanálise; e o que é subjetividade (psicanálise) para o transfeminismo e a medicina. Num segundo momento, no entanto, coube problematizar o fato de que as 'verdades' produzidas por cada um desses campos não são fatos inquestionáveis, mas construções discursivas. Considera-se aqui uma perspectiva foucaultiana - em que o discurso não copia ou traduz a realidade. Ele constrói um conhecimento sobre ela, mas um conhecimento que delimita categorias de pensamento e estabelece o alcance de argumentos cuja utilização é possível. As verdades, dentro de cada discurso, não surgem sem uma relação com o poder que as autoriza ou as nega. Ora, pode-se certamente considerar que os discursos sobre a transexualidade e o corpo trans estão inscritos na ideia de controle dos corpos e da população, que Michel Foucault (1999) convencionou chamar de biopoder.

Como poder de promover a vida ou desautorizá-la ao ponto da morte (FOUCAULT, 1999), o biopoder controla os corpos porque é internalizado por cada um de nós, através de normas, e porque está disperso por toda a sociedade, em vez de localizado nas mãos de um governante ou de uma única instituição.

Quais os regimes de verdade presentes nos discursos inscritos no biopoder que se apropria da vida humana? A biopolítica da população, que intervém para regular e controlar processos biológicos como nível de saúde, nascimento, mortalidade e longevidade, opera necessariamente sobre sexo e gênero, aspectos que se encontram no coração de problemas econômicos e políticos. Se, por exemplo, a reprodução há que ser garantida, o corpo útil deve obedecer à heteronormatividade. Não é de se estranhar que sejam qualificadas como doença as manifestações de corpos que escapam a essa norma. É o que vemos na história da medicina. No caso dos corpos trans, uma 'solução' encontrada em alguns países, como, por exemplo, na França, foi a cirurgia de redesignação sexual condicionada a uma política de esterilização. Sem dúvida, o Estado regula os corpos trans através de suas instituições e por meio da própria internalização das normas de sexo e de gênero.

\section{Saúde/doença e intervenções: discurso médico}

O binômio saúde/doença aparece como categoria central no discurso médico sobre o corpo das pessoas trans, orientando o saber e a prática interventiva sobre o 'doente'. Ao identificar a doença, deve-se promover a transição dessa condição para a de saúde. Mas no próprio ato de nomear uma determinada condição, o saber médico inventa a sua 'descoberta'. É assim que a produção da transexualidade enquanto doença é atrelada ao seu diagnóstico e 'cura', através da intervenção corporal. A descoberta da transexualidade é atribuída a Harry Benjamin, endocrinologista e sexólogo americano, na década de 60.

O que se deve levar em consideração, porém, analisando o discurso médico, é que a própria origem do termo transexual, relacionada ao trânsito entre os gêneros e concebida enquanto desejo de mudança de sexo, é devedora de uma história da sexualidade com diferentes concepções de sexo e de gênero (Thomas LAQUEUR, 2001). A mistura do masculino e feminino sempre existiu e passou a ser codificada como doença em uma trajetória que não necessariamente é linear: da antiguidade até o século XVIII, encontrava-se na figura do hermafrodita/andrógino a representação da união do masculino/feminino em um mesmo ser. Prevalecia até esse momento a ideia de um só corpo para os dois gêneros. Com o desenvolvimento das ciências sexuais e da 'sexualidade', no século XVIII, o corpo passou a ser dois, um para cada gênero e a identificação da diferença dos corpos se concentrou sobre os órgãos sexuais. Nesse momento, surge a figura do pseudo-hermafrodita, "fruto da ciência médica e psíquica, da nova visão fisiológica de dois sexos e dois gêneros distintos" (Jorge LEITE JR., 201 1, p. 34). A partir desse momento histórico, o não binário passa a pertencer ao campo da doença e, consequentemente, se torna objeto de estudo da medicina. Ou seja, a mistura do masculino e feminino passou a ser considerada como um desvio, uma anormalidade, uma falha em relação a uma ordem natural. O termo transexual só aparece no século XX, mas já nasce herdeiro dessa lógica que concebe a mistura entre masculino e feminino nesses termos.

A falha, desvio ou anormalidade relativa ao gênero, na concepção médica, produzem, por parte do 'doente', uma condição subjetiva que implica o sofrimento. Ao se analisar o discurso médico, encontram-se inúmeras descrições que atribuem ao paciente diferentes graus de incômodo e mal-estar que culminam na ideia de sofrimento - como estado próprio da condição de doença. Não importa aí se a causa eventual do sofrimento é de ordem social. O sofrimento legitima o saber/poder médico em relação às pessoas trans, mas, cabe aqui dizer, de certo modo também legitimará o saber psicanalítico. Em que pese as diferenças entre as abordagens psicanalíticas, é comum o discurso de que pacientes trans sofram com a sua condição. 
A ideia de sofrimento vem contrária à ideia de bem-estar, elencada no conceito de saúde. Ele é significado como algo negativo, e a medicina vem ofertar um potencial de cura, não apenas da doença, mas também do próprio sofrimento. Dessa maneira, o sofrimento parece funcionar como um operador das decisões médicas em relação aos pedidos de modificação corporal por parte das pessoas trans, ou seja, novamente se observa uma inversão no mesmo sentido da invenção de uma doença. É preciso estar sofrendo, como pré-requisito para acessar a possibilidade de modificar o corpo. Ora, como bem sabemos, nem todas as pessoas trans sofrem e, se sofrem, não se trata do mesmo sofrimento para todas elas, nem do mesmo sofrimento identificado na produção discursiva do campo médico.

Percebe-se que, para construir a ideia de uma doença em que se percebe sofrimento, é preciso que haja no discurso médico uma definição de saúde. A Organização Mundial de Saúde (OMS) define saúde como sendo não apenas a ausência de doença, mas um estado de completo bem-estar físico, mental e social. Considerando a dificuldade em se obter bem-estar social frente a situações de preconceito e violência, tão comuns na experiência de vida cotidiana de pessoas trans, pode-se argumentar que dificilmente se atingiria o ideal de saúde proposto. À medida que um estado de completo bem-estar físico, mental e social parece ser impossível ou destinado a poucos, quem não apresenta essas condições pode, de algum modo, ser considerado doente pela medicina. Neste sentido, mesmo que a transexualidade seja retirada dos manuais de doença, há um risco de ela flertar com a condição patológica. O ideal de saúde inalcançável revelaria que, de alguma forma, somos todos doentes, mas certamente uns podem ser mais doentes do que outros.

Podemos pensar que a condição de doença ou de ausência de bem-estar levaria o sujeito a renunciar a sua autonomia em relação ao corpo. Abrir mão, nesse sentido, poderia ser uma escolha forçada, ou seja, quando se entende que depender do discurso médico seria a última ou a única alternativa para atingir aquilo que se deseja. Muitos 'casos' de transexualidade parecem se encaixar nesse âmbito. A autonomia, tão cara ao discurso transfeminista, é deslocada das pessoas trans para a medicina, na medida em que esta pode diagnosticar a 'doença' e erradicar o 'sofrimento', estabelecendo o estado de 'saúde'.

Mas a intricada rede discursiva prevê ainda outra categoria. O binômio saúde/doença não anda separado da etiologia da transexualidade. A revisão bibliográfica parece sugerir que não existe nenhuma descoberta conclusiva comprovando a existência de uma gênese biológica da transexualidade (Alexandre SAADEH, 2004; Giancarlo SPIZZIRRI, 2015), no entanto, a sua busca é incessante. Existem diversas hipóteses, algumas mais aceitas do que outras. O encontro de uma etiologia biológica seria relevante para o campo médico, na medida em que se acreditaria colocar um ponto final na discussão que envolve o transfeminismo, as ciências sociais e a psicanálise acerca de quem teria legitimidade para decidir, intervir e falar sobre o corpo das pessoas trans. O que merece destaque é que essa base biológica não foi encontrada, talvez nunca o seja, mas, ainda assim, o discurso médico reconhecido como científico assume valor de verdade e, em nome desta, muitas vezes produz absurdos, como atestam laudos, avaliações, protocolos, conduções de tratamento e mesmo comportamentos em relação a pessoas trans, isentos de rigor e princípios básicos de respeito ao 'objeto' investigado.

A invenção da doença, o estabelecimento de um padrão de saúde inalcançável, a determinação do sofrimento como condição subjetiva e a busca da etiologia como fundamento da legitimidade do poder médico sobre as pessoas trans são as categorias que fazem parte de uma trama discursiva que se sustenta nela mesma. Nesse sentido, como qualquer discurso, é regido por uma opacidade que nos coloca a tarefa de problematizá-lo.

Antes mesmo de ocupar o lugar de doença e anormalidade na atualidade, por ocasião do surgimento do termo transexualismo, o transitar entre os gêneros masculino e feminino já havia sido banido de um lugar de saúde e de normalidade, como mostra a própria história das ciências sexuais (LEITE JR., 2011). O lugar de doente foi o que restou, ou seja, a transexualidade não está lá por apresentar características de doença (como uma etiologia de base biológica poderia supor), mas por não se encaixar no modelo de saúde em que a coerência entre gênero e sexo anatômico está suposta. Esse ponto incide diretamente sobre como o corpo da pessoa trans é encarado pela medicina. A partir do momento em que se estabelece um modelo do que é considerado um corpo normal e com saúde, o que não se encaixa é impedido de pertencer ao campo da normalidade. A condição de doente torna o corpo da pessoa trans objeto de estudo (pesquisável, classificável e fragmentado) e a busca pela etiologia revela uma face de um corpo frio, morto. Nessa medida, o que está em jogo no discurso médico sobre a pessoa trans é apenas o corpo biológico, não aparecendo nem a dimensão da subjetividade e nem a dimensão política. Se considerarmos, como sugere o discurso psicanalítico, que existem aspectos relativos ao desejo, ao erótico e à fantasia expressos nas demandas de modificações corporais e que eles são excluídos do discurso médico sobre o corpo da pessoa trans, podemos identificar que um silenciamento é pressuposto e que este pode vir a ser entendido como uma violência, como bem o ilustra o discurso transfeminista. 


\section{Política e autonomia: discurso transfeminista}

Quem se aproxima do discurso transfeminista percebe logo de saída que ele põe em evidência, através de livros e blogs na internet, a categoria de autonomia. Transfeministas brasileiras, como Hailey Kaas Alves e Jaqueline Gomes de Jesus (2012), abordam de modo direto a reivindicação do poder de decisão das pessoas trans sobre seus corpos. O tipo de luta política sugerida nesse discurso sugere aproximação com algumas pautas feministas clássicas.

O feminismo de base biologizante, por exemplo, apesar de ser questionado pelo transfeminismo em função de suas premissas essencialistas, tem em comum o motivo de surgimento dos movimentos em si: a emancipação, o protagonismo nas lutas e o direito sobre o corpo enquanto pauta da agenda política. A reivindicação pela liberdade do uso do próprio corpo e o respeito às suas especificidades é pauta do feminismo desde a segunda onda (Céli Regina PINTO, 2010). Desse modo, não se trata de uma exclusividade do movimento transfeminista. No entanto, há uma especificidade a ser considerada: em sua história de reivindicação pelo direito de realizar intervenções corporais, o corpo trans se encontra patologizado por saberes científicos. O desejo de emancipação e a reação ao discurso médico conferem ao corpo trans um novo sentido para autonomia, a decisão sobre a condição de saúde/doença. Emerge do discurso transfeminista a ideia de que o corpo se encontra em correspondência direta com quem o habita. Ele ocupa um duplo lugar político. Atua como protagonista, se assume como sujeito, ou seja, a pessoa trans é agente de uma luta. Mas uma luta cuja pauta é o corpo, objeto de disputa e intervenção. O corpo trans, nessa perspectiva, se apresenta tanto num lugar ativo, como sujeito que luta, como num lugar passivo, como objeto a ser debatido e defendido.

Mas quem seria, então, essa pessoa trans, no discurso transfeminista, detentora da verdade e do poder de agência sobre seu corpo? As categorias gênero e mulher surgem numa segunda leitura e parecem dar resposta a essa pergunta. O corpo que luta e fala de si se associa duplamente ao gênero, seja pelo viés médico-psicológico, seja pelo campo de estudos que problematiza a identidade mulher, os estudos feministas, de mulheres e de gênero (Miriam Pillar GROSSI, 2004; Judith BUTLER, 2003).

O discurso transfeminista volta-se para a origem do conceito de gênero, utilizado pelo psicólogo John Money, na década de 50 (apud ALVES; JESUS, 2012), em seu estudo acerca dos papéis sociais de homens e mulheres. Gênero apontaria as diferenças entre os conjuntos de características que definiriam esses papéis, diferenciando-se do conceito de sexo biológico. Mas, nem sempre a expectativa social relacionada ao gênero atribuído ao nascimento, em função do sexo biológico, foi correspondida pela identificação ao gênero adotado posteriormente (JESUS; ALVES, 2012). Acompanhando Money, vemos o conceito de núcleo de identidade de gênero do psiquiatra e psicanalista Robert Stoller (1982), criado na década de sessenta, igualmente tomando parte como referência para o debate transfeminista. Se, por um lado, Stoller teoriza a separação sexo/gênero do ponto de vista psicológico, por outro lado, introduz essa experiência no campo dos distúrbios mentais. De sua parte, o discurso transfeminista se posicionará numa perspectiva de desconstrução da transexualidade enquanto uma patologia. Quem habita o corpo trans não é uma pessoa doente. Trata-se de uma autopercepção, de uma experiência identitária. Perceber-se como mulher é ser mulher. Nesse sentido, perceber-se como mulher é ir ao encontro do questionamento feito em determinado momento da história do movimento feminista sobre as diferentes mulheres e o quanto elas estavam ou não sendo contempladas na ideia supostamente universal de mulher.

O termo mulher, que inicialmente foi usado para fortalecer o sentimento de identidade, representava apenas as mulheres cisgêneras, brancas, de classe média e heterossexuais (Mara C. de Souza LAGO, 2012; Silvana MARIANO, 2005; Martha NARVAZ; Silvia KOLLER, 2006). Críticas surgem a partir do pronunciamento de 'outras' mulheres que não estavam inclusas na ideia de uma unidade, como as mulheres negras, lésbicas, trans, entre outras. A expansão dos temas feministas dará início, na década de 90 , à chamada terceira onda feminista.

Paralelamente a essa ampliação, opera-se um deslocamento gradual do termo mulher como categoria central do feminismo para o termo gênero. Este, num primeiro momento, entra como um conceito que vem reforçar a categoria mulher, inserindo-se no feminismo da segunda onda como um marcador da diferença sexual (Adriana PISCITELLI, 2009). A perspectiva que aponta para determinantes relacionais na construção do ser mulher, no período pós-guerra, bota em cena as diferenças biológicas, sociais e culturais entre os gêneros (LAGO, 2012). Na perspectiva transfeminista, essa vertente dos Estudos de Gênero privilegia a ideia de um binarismo (homem ou mulher) e sustenta a subordinação do termo mulher ao sexo biológico. O corpo, nesse campo, se assemelharia ao corpo biológico da medicina, cujo foco se encontra nos órgãos sexuais como aparato para diferenciar homens e mulheres. Parte do movimento transfeminista não tardou a criticar essa posição sugerindo, inclusive, abolir a ideia de que existam gêneros binários (homem e mulher) (JESUS, 2015, p. 21). 
Mas impulsionados pelo diálogo com o pós-estruturalismo, os estudos de gênero abrem espaço para o questionamento de identidades fixas e universais para as diferentes mulheres e transformam gênero numa ferramenta relacional e política (Joan SCOIT, 1995). O corpo, nessa perspectiva, se distancia do corpo apenas biológico da medicina e do foco nos órgãos sexuais e se aproxima de um corpo que possui história e marcas, que habita um determinado contexto e espaço social, que possui cor de pele, que se comporta de diferentes maneiras e exerce diferentes sexualidades. Aparece a dimensão política do corpo, que envolve a subjetividade, além de sua materialidade.

De certo modo, o discurso transfeminista encampa a problematização do termo mulher, de sua substituição pelo termo gênero, do questionamento das diversas formas de ser mulher e, nessa medida, ao lado do movimento feminista, produz uma verdade sobre o corpo trans.

Além de agência/autonomia, surge na agenda transfeminista outras pautas. Primeiramente, o combate à violência cissexista/transfóbica (simbólica, psicológica, física, entre outras). A violência simbólica surge, por exemplo, no uso que se faz dos discursos médicos e psicanalíticos frente às questões do corpo trans, transformando-o em corpos doentes, manipuláveis, silenciados. Em seguida, vemos os direitos reprodutivos, que concernem ao direito a uma gestação ou aborto seguros para homens trans e a não esterilização compulsória de mulheres trans, e que põem em relevo a violência física e psicológica. Essa pauta de luta pode ser, de alguma forma, compartilhada com a questão da legalização do aborto para as mulheres cisgêneras, lembrando-nos de que não é uma exclusividade do discurso transfeminista a queixa contra a submissão do corpo ao poder médico e jurídico. Vemos, ainda, a pauta sobre a livre sexualidade, em que se pretende estimular que as pessoas trans se sintam confortáveis com a sua orientação sexual, seja ela qual for. Essa pauta existe pelo pressuposto da medicina de que as pessoas transexuais são supostamente assexuais ou heterossexuais. Agência/autonomia estão presentes em todas as pautas de luta transfeministas. Pretende-se libertar o corpo das visões essencialistas que subordinam o gênero ao sexo biológico. Além disso, ao se aliar a algumas pautas das mulheres cisgêneras, revela-se uma face da luta acerca da hierarquia entre os gêneros. Nesse sentido, não se pretende substituir ou apagar lutas comuns às mulheres cisgêneras, embora o objetivo maior seja o de evidenciar as questões específicas das pessoas trans. Segundo Alves (2013), o transfeminismo pretende formar alianças nessas lutas. Quando os corpos cisgênero ou transgênero debatem politicamente a sua submissão às instâncias de poder, eles acabam por ser aproximados. Nesse sentido, é importante, como apontado por Alves (2013), não fazer uma distinção entre categorias trans e cis no que tange à análise dos corpos, comportamentos e identidades quando a discussão é sobre o que é normal ou natural e, talvez possamos acrescentar, entre o que é saúde e o que é doença. Essas pontuações permitem delinear um lugar político de destaque para o corpo no transfeminismo, em que se revela uma face de direitos do corpo. Desse modo, nem a face biológica do corpo e nem a subjetiva são o foco desse olhar, mesmo se ambas estão presentes. Um corpo de direitos, como propõe o transfeminismo, dificulta que a transexualidade seja objeto de discussões e argumentações de certos discursos (como o da medicina e de algumas psicanálises) que a patologizam. Ou seja, o diálogo que poderia ser estabelecido, nessa perspectiva, com o discurso médico e com a psicanálise, deveria ultrapassar o âmbito da saúde e atingir o dos direitos humanos.

Corpo, gênero, mulher, agência, autonomia, violência, lutas, direitos, corpo político. Um corpo que não é doente, mas habitado por um sujeito político, sujeito de direitos. $O$ discurso transfeminista, em sua trama, propõe, entre outras verdades, a da propriedade sobre o próprio corpo. Se os discursos sobre os corpos sempre revelam uma dimensão de poder, o discurso transfeminista declara o poder da pessoa trans sobre ela mesma, sugerindo uma certa independência em relação a outros saberes, sejam eles quais forem.

\section{Subjetividade e identidade: psicanálise}

Frente à ideia de um ideal de saúde vemos o discurso psicanalítico surgir com uma concepção radicalmente distinta. A psicanálise recusa a ideia de um bem-estar completo, pois considera que o conflito psíquico é constitutivo da existência humana, não sendo possível livrar-se dele. Sigmund Freud (2006c[1923]) apresenta essa ideia em diversos momentos de sua teoria, evidenciando que a satisfação jamais é plena, seja pelo conflito interno - por exemplo, o que interessa ao id difere do que interessa ao ego ou ao superego, seja pelo conflito com o mundo externo - a realidade impõe limites à satisfação das pulsões (FREUD, 2006a[1895]; 2006b[1905]; 2006c[1923]). Mais do que isso, em O mal-estar da civilização, Freud (2006d[1930]) dirá que a vida social só é possível porque renunciamos a uma grande parcela de satisfação de nossos desejos.

Examinando o discurso psicanalítico vemos aparecer como central a categoria subjetividade que, mesmo não sendo um conceito próprio da psicanálise, abarca elementos como sentimentos, fantasias, desejos - conscientes e inconscientes. Por essa perspectiva, é impossível aderir ao protagonismo de um conceito como o de agência/autonomia. Motivações conscientes, que dão sustentação à nossa autonomia, não dão conta suficientemente de nossa relação com o mundo, 
há que se caminhar com cautela quando se trata de grandes mudanças em nossa vida. Ainda assim, leituras distintas dos pressupostos teóricos e conceitos de Freud permitem a existência de diferentes abordagens psicanalíticas e, consequentemente, variadas perspectivas sobre a transexualidade e as modificações corporais por parte de pessoas trans.

Para a psicanálise, o corpo pode se apresentar como palco e personagem das relações entre o psíquico e o somático (Maria Helena FERNANDES, 2003). Ele não corresponde ao corpo biológico, objeto da medicina, que chamamos anteriormente de corpo frio e manipulável. No trabalho clínico com os casos de histeria, Freud interpreta o sintoma corporal (paralisia, anestesia, cegueira temporária etc.) como expressão e símbolo de um conflito psíquico (FREUD, 2006a[1895]). Nele se esconde um sentido. Ele fala, mas também silencia. A partir da teoria das pulsões, o corpo se transforma em corpo erógeno (FREUD, 2006b[1905]) - investido libidinalmente por um outro, desde o nascimento do bebê - e permanecerá, de vez, entrelaçado à constituição do sujeito psíquico. Corpo e subjetividade são conceitos inextricáveis na psicanálise.

Essa forma de conceber a relação entre corpo e sujeito permite supor que alterações no plano biológico e material podem afetar e alterar o plano psíquico e vice-versa. A emissão de laudos ou pareceres autorizando intervenções sobre o corpo de pessoas trans seria uma forma de se pronunciar acerca de sua condição psíquica para suportar mudanças que também serão psíquicas, mas, igualmente, sobre possíveis benefícios psíquicos das intervenções sobre o corpo. A partir daí, vemos surgir diferentes discursos psicanalíticos abordando essa questão.

O discurso que funda a aproximação da psicanálise com a transexualidade é a teoria formulada na década de 60, por Robert Stoller (1982), psiquiatra e psicanalista americano. Jacques Lacan (2009), ao retomar a obra de Stoller, dá início a uma nova corrente de pensamento sobre a transexualidade, com desenvolvimentos de alguns de seus seguidores próximos (Catherine MILLOT, 1992; Moustapha SAFOUAN, 1979; Marcel CZERMAK, 1982). A corrente lacaniana faz eco no Brasil, primeiramente, numa perspectiva ortodoxa (Marina TEIXEIRA 2006; Doris RINALDI, 2011), abrindo-se para novas contribuições, em diálogo com as teorias feministas, os estudos de gênero e a teoria queer (Rafael Kalaf COSSI, 2011; Pedro AMBRA, 2015), ou se posicionando contra esses (JORGE; TRAVASSOS, 2018). Por último, examinamos uma perspectiva psicanalítica que se aproxima de Foucault e dos estudos queer (Márcia ARÁN, 2006; 2009; Thamy AYOUCH, 2015; Patricia PORCHAT, 2014a).

Além de subjetividade, destacam-se no discurso psicanalítico as categorias patologia, constituição do Eu, gênero, identidade e modificação/intervenção corporal.

O diagnóstico de transexualidade enquanto patologia mental, seja como distúrbio profundo do Eu (STOLLER, 1982) que prevê a correspondência da identidade de gênero com o sexo anatômico, seja como psicose, mesmo que relativizado como doença no interior do quadro conceitual lacaniano, ainda assim, traz problemas para as pessoas trans. Os termos distúrbio e psicose circulam também em discursos não psicanalíticos e possuem uma conotação estigmatizante. Quando vemos as pessoas trans serem descritas em termos que, mesmo sutis, sugerem uma doença, o discurso psicanalítico flerta com o discurso médico.

Uma das queixas relativas à psicanálise stolleriana, a alguns psicanalistas lacanianos e à medicina é a de que as explicações e critérios médicos e psicanalíticos não abarcam as múltiplas expressões e maneiras de viver a transexualidade. Esse aspecto é contemplado ao se propor que a transexualidade é a expressão de uma experiência identitária, que só pode ser compreendida de maneira singular (ARÁN, 2006; AYOUCH, 2015; PORCHAT, 2014a). Transidentidades foi a saída terminológica encontrada por Ayouch (2016). A palavra identidade, no termo transidentidades, marca a pluralidade das construções de gênero, além de ser um termo criado fora do discurso médico, como transexual ou travesti. Percebe-se, finalmente, que no discurso psicanalítico é possível tanto produzir um lugar de doença para as pessoas trans, quanto o de uma identidade. Aproximações com o discurso médico e com o discurso transfeminista ficam aqui evidentes.

As perspectivas stolleriana e lacaniana, apesar de diferentes, possuem pontos em comum. Ambas localizam suas explicações sobre a transexualidade na infância (distúrbio profundo do Eu e estrutura de psicose). A origem da transexualidade estaria no período anterior ao complexo de Édipo, em que existe uma primazia da relação da criança com a mãe, situação em que se dá a constituição do Eu. Numa leitura de gênero, pode-se arriscar dizer que parece residir nessas explicações uma valorização do gênero masculino em detrimento do feminino: Stoller enfatiza um excesso prejudicial do feminino (intensa simbiose da criança com a mãe por um longo período); já em Lacan, a ênfase é colocada na ausência do masculino (o significante Nome do Pai não é inscrito simbolicamente). Leituras ingênuas que colam a psicanálise ao senso comum veem nesse tipo de explicação a configuração de um quadro de risco: famílias não equilibradas emocionalmente produziriam pessoas trans. Pessoas trans seriam oriundas de famílias não equilibradas emocionalmente. Esse tipo de raciocínio, bastante perigoso, preconceituoso e estigmatizante, frequentemente anda junto com a busca por etiologias, tão cara ao discurso médico. 
Ayouch (2015) afirma que "quando a psicanálise considera a transexualidade como uma categoria que existe ontologicamente, em si, ela se torna antipsicanalítica, produzindo uma resistência a si mesma e ao seu exterior" (p. 24). Nesse sentido, Ayouch atribui a Stoller e à abordagem lacaniana uma filiação psiquiátrica. Um caminho possível para que a psicanálise possa conversar com as transidentidades seria realizar uma 'inversão das questões trans', que consiste em questionar o que essas identificações, seu empoderamento e visibilidade podem revelar do funcionamento de um tipo de discurso psicanalítico e de suas metas de poder, trazendo à tona a dimensão política da psicanálise e os efeitos de poder do seu saber (AYOUCH, 2016, p. 4). Ou seja, pensar a transexualidade de uma maneira não patologizante, via psicanálise, já é estar em um campo político e de articulação com outros saberes (antropologia, movimentos sociais, transfeminismo, entre outros). Ainda, despatologizar a transexualidade no interior do discurso psicanalítico é encontrar no próprio conceito de gênero e na expectativa de coerência entre sexo anatômico e gênero a origem do estabelecimento da transexualidade como patologia.

A desconstrução do conceito de gênero por Butler (2003) e, em especial, seu diálogo com a psicanálise, colocou aos psicanalistas a tarefa de dizer o que entendem por gênero. Gênero e identidade aparecem na obra de Stoller (1982), mas estavam ausentes da perspectiva lacaniana. Trabalhos recentes como os de Cossi (2011) e Ambra (2015), no Brasil, passam a incorporar esse debate, reconhecendo a crítica de Butler, problematizando aspectos da obra de Lacan e propondo alternativas, ainda no interior da obra lacaniana.

Em Stoller (1982), gênero se aproxima do discurso médico, na medida em que se espera uma correspondência entre gênero e sexo anatômico de nascimento, considerado um dado biológico e natural. Já o termo identidade funciona como uma categoria excludente: só seria possível possuir uma identidade de gênero (feminina ou masculina) não existindo outras possibilidades. Contrapondose a essa ideia, trabalhar com o termo transidentidades permite contestar a subordinação do gênero ao sexo biológico, o que sugere que gênero não precisa ser necessariamente binário (masculino ou feminino). O diálogo com Foucault e com Butler permite desconstruir a ideia de gênero pressuposta na medicina, na psiquiatria e herdada pela psicanálise, problematizar as relações de poder existentes no interior desses discursos e analisar a produção dos gêneros estáveis, dos gêneros dissonantes e não inteligíveis, além da própria condição suposta de doença e sofrimento das pessoas trans. Mas, em última instância, a psicanálise que trabalha com as transidentidades também é uma produção discursiva. Retornaremos a isso nas considerações finais.

Voltando à ideia de que corpo e subjetividade são inseparáveis para a psicanálise, é possível falar de constituição do eu sem estabelecer laços com a etiologia da transexualidade. Duas premissas freudianas são aqui fundamentais: a primeira é a de que o eu é um eu corporal. Por ser responsável pelas percepções, tanto internas como externas, Freud (2006c[1923]) afirma que o eu é "primeiro e acima de tudo, um eu corporal; não é simplesmente uma entidade de superfície, mas é, ele próprio, a projeção de uma superfície" (p. 17). Em segundo lugar, a psicanálise dá destaque ao papel do outro na constituição do corpo. O corpo seria atravessado tanto pelo discurso como pelo desejo do outro, revelando a existência de um aspecto intersubjetivo.

Vemos acima como a constituição do Eu ou do corpo-subjetividade pode ser pensada como produtora de diferenças. Diferentes percepções e diferentes outros nos habitam. Butler (2015) se apropria da teoria dos significantes enigmáticos do psicanalista Jean Laplanche para compreender a dimensão inconsciente e pulsional do gênero enquanto ato performativo. O eu se constitui, desde bebê, investido libidinalmente e marcado por um outro (ou mais), que lhe inunda de significantes incompreensíveis nesse momento da vida. O outro é uma espécie de causa ou fundamento do inconsciente. As primeiras impressões que vêm do outro são excessivas, enigmáticas, a criança não tem condições de compreendê-lo. O inconsciente, na verdade, se constrói como uma forma de manejar esse excesso (LAPLANCHE 1999, apud BUTLER, 2015, p. 75). Aquilo que em nós é incoerente, indizível, subversivo (no caso de gênero) vem, finalmente, do outro (PORCHAT, 2014c). Na linha da desconstrução do gênero binário e estável, que permite alocar transidentidades e identidades cis lado a lado, incoerência e subversão são aqui termos positivos em relação ao gênero e à identidade no discurso psicanalítico, são da ordem da potência de produção e não apenas da repetição.

Por último, a noção de eu corporal permite uma aproximação com a questão das modificações corporais. Se considerarmos que o sujeito e corpo são inseparáveis, as modificações corporais poderiam ser compreendidas como uma "invenção de si" (PORCHAT, 2014b), como uma maneira de construir identidade, e não concebida enquanto tratamento de uma doença, como proposto pelo discurso médico. Na psicanálise de Stoller, as modificações corporais seriam uma forma de tratamento, já que uma vez formado o núcleo de identidade de gênero na infância, ele não mais se alteraria e a cirurgia seria a melhor solução para o distúrbio. Já em abordagens lacanianas ortodoxas, modificar o corpo não resultaria necessariamente em um efeito terapêutico. Pelo contrário, poderia até suscitar maior sofrimento psíquico em alguns casos, principalmente se considerada a transexualidade como uma psicose. Modificar o corpo real, físico, nessa perspectiva, não proporcionaria ao sujeito a mudança psíquica almejada. 
O que distanciaria a posição lacaniana ortodoxa do saber médico e do transfeminismo seria a recomendação de não intervir no corpo. Isso confronta a medicina, para quem as modificações funcionam como uma forma de tratamento, e confronta o transfeminismo, para quem essa posição retira qualquer possibilidade de autonomia de decidir sobre o próprio corpo.

No discurso psicanalítico, que entende as experiências trans como identitárias, assume-se a postura de que as modificações corporais podem ser uma escolha legítima. Participar de algum modo da possibilidade de intervenção corporal em pessoas trans envolveria tanto aspectos éticos como políticos. Nesse sentido, critica-se a postura de médicos que sugerem ou mesmo induzem as modificações corporais; de psicanalistas que são contrários a elas a priori, e o impedimento de modificações corporais a pessoas trans que não se encaixam no perfil de transexual 'verdadeiro', de acordo com o discurso médico e com certa interpretação psicanalítica de Lacan. Enquanto os critérios para as modificações corporais estiverem subordinados a uma classificação de doença, a autonomia das pessoas trans se limita a se autoproclamarem doentes. As teorias patologizantes continuarão sendo aplicadas, pois haverá sujeitos trans se adequando a esses critérios e perpetuando a validade dessas teorias.

Quanto à psicoterapia, poderia eventualmente ser um espaço em que o sujeito identifique as relações entre essa escolha e seus desejos, além de outras questões. Para que isso ocorra, é necessário que o corpo da pessoa trans não seja desconsiderado em nenhum âmbito (biológico, subjetivo, político) pela psicanálise. Assim, estaríamos de fato reconhecendo um corpo-sujeito.

Finalizamos a análise dos três discursos percebendo que encontramos a produção de sujeitos políticos e autônomos em suas decisões (transfeminismo), sofredores, doentes ou determinados a atingir o ideal do bem-estar (medicina), portadores de uma diferença mental ${ }^{3}$ ou experimentadores da identidade (psicanálise).

\section{Considerações finais}

Pronunciamentos sobre o corpo trans nos inserem numa rede discursiva que ajudamos a produzir, mas que também nos captura. Medicina, psicanálise e transfeminismo, nesta pesquisa servindo como porta-vozes das pessoas trans, todos representam um papel no que poderíamos até chamar, parafraseando Foucault (1999), de dispositivo da transexualidade. Os arranjos de poder dispersos nas práticas médicas, psicanalíticas e mesmo no exercício da militância produzem diferentes verdades sobre as pessoas trans e seus corpos que, mesmo tendo uma realidade material, estão submetidos a afirmações, negações, teorias e reivindicações vindas dos mais variados domínios. Analisamos apenas três, pois é justamente essa realidade material, a do corpo, que torna a situação um palco de disputa. "Quem habita o corpo trans?" poderia ser substituído por "Quem controla o corpo trans?". Medicina, psicanálise e transfeminismo se autorizam a produzir suas verdades. O poder que controla os corpos está internalizado em cada um de nós, disperso pela sociedade. Mas uma sociedade que tem história e, por isso mesmo, muda. Em nossa análise, limitada pela necessidade de um recorte de campo de pesquisa, a história da verdade e o controle sobre o corpo trans começam com a medicina e com a psicanálise, deslocam-se para a militância do movimento transfeminista, e reencontram uma parte da psicanálise, em parceria com o transfeminismo. Contradições necessariamente emergem.

O discurso transfeminista, ao propor, entre outras verdades, a do sujeito autônomo em suas decisões, vai de encontro à ideia psicanalítica da existência de um inconsciente, de um sujeito dividido. Para essa psicanálise, o discurso transfeminista parece propor uma postura que generaliza as próprias pessoas trans. Teríamos todos nós, trans e cis, autonomia suficiente para decidir sobre nossas vidas e nossos corpos? Muitos certamente sim, talvez a maioria sim, talvez não. Haveria uma dimensão inconsciente a ser considerada.

Mas também na psicanálise encontramos um discurso que retira a autonomia das pessoas trans, ao adotar, assim como o discurso médico, uma postura de saber exclusivo, de diagnóstico e avaliação. Essa postura exclui a experiência da pessoa em questão, ou seja, da pessoa a quem interessa modificar o corpo, em função de sua autopercepção. Mais do que isso, ao não escutá-la, a psicanálise pode reduzi-la a um quadro conceitual previamente estabelecido, vazio, sem sujeito falante. Quase como se fosse o corpo frio da medicina, ao qual nenhuma subjetividade é atribuída. ${ }^{4}$

Por último, a psicanálise também pode entender que essa é uma questão política e ética. Mas mesmo privilegiando a experiência transidentitária, essa psicanálise não escapa de analisar a sua própria condição de ser produzida enquanto teoria e igualmente produzir verdades. Afinal, ela também é uma produção discursiva. É essa análise que pode iluminar a opacidade do discurso, aquilo que ele deixa de fora para se constituir, isto é, os limites que o constituem.

\footnotetext{
${ }^{3}$ Sugerimos esse termo para nomear o distúrbio do Eu (STOLLER, 1982), a psicose (LACAN, 2009[1971]), e incluir as novas propostas, como as de desmentido (COSSI, 2011) e histeria (JORGE; TRAVASSOS, 2018).

${ }^{4}$ Algumas equipes médicas em ambulatórios especializados em cuidados para pessoas trans têm feito o movimento na direção de uma visão global, que inclui a dimensão política e subjetiva da questão.
} 
Talvez possamos recorrer à própria concepção freudiana de corpo. Ao considerarmos que a transexualidade não é uma doença e que não possui uma dinâmica específica de funcionamento comum a todos as pessoas trans, não existiria um corpo trans específico para a psicanálise. Há apenas corpos-sujeitos. Nomeá-los é outra história.

Existem condições para dialogar a partir de diferentes discursos. Porém, coloca-se uma questão primordial: será que suportamos nossas diferenças e limites? Será que nos dispomos a analisar a produção de nossa própria fala? Não há outro jeito.

\section{Referênclas}

ALVES, Hailey Kaas. "O que é e porque precisamos do transfeminismo". In: SAKAMOTO, Leonardo; MANO; Maíra Kubik (Orgs.). A quem pertence o corpo da mulher? Reportagens e ensaios. São Paulo: Repórter Brasil, 2013. Disponível em http://transfeminismo.com/o-que-e-transfeminismo-umabreve-introducao/. Acesso em 15/09/2016.

ALVES, Hailey Kaas; JESUS, Jaqueline Gomes de. "Feminismo transgênero e movimentos de mulheres transexuais". Revista Cronos, Natal, v. 11, n. 2, p. 8-19, nov. 2012.

AMBRA, Pedro. O que é um homem? Psicanálise e história da masculinidade no Ocidente. São Paulo: Annablume, 2015.

ARÁN, Márcia. "A transexualidade e a gramática normativa do sistema sexo-gênero". Revista Ágora, Rio de Janeiro, v. 9, n. 1, p. 49-63, jan./jun. 2006.

ARÁN, Márcia. "A psicanálise e o dispositivo diferença sexual". Revista Estudos Feministas, Florianópolis, v. 17, n. 3, p. 653-673, set./dez. 2009.

AYOUCH, Thamy. "Da transexualidade às transidentidades: psicanálise e gêneros plurais". Revista Percurso 54, São Paulo, p. 23-32, jun. 2015.

AYOUCH, Thamy. "Quem tem medo dos saberes T.? Psicanálise, estudos transgêneros, saberes situados". Revista Periódiocus, Salvador, v. 1, n. 5, p. 3-6, maio/out. 2016.

BARDIN, Laurence. Análise de Conteúdo. São Paulo: Edições 70-Brasil, 2011.

BUTLER, Judith. Problemas de gênero: feminismo e subversão da identidade. Rio de Janeiro: Civilização Brasileira, 2003.

BUTLER, Judith. Relatar a si mesmo: crítica da violência ética. Belo Horizonte: Autêntica, 2015.

CFM. Resolução CFM n 1.482/97. Brasília: Conselho Federal de Medicina, 1997. p. 20944. Disponível em http://www.portalmedico.org.br/resolucoes/CFM/1997/1482_1997.htm.

COSSI, Rafael Kalaf. Corpo em obra: contribuições para a clínica psicanalítica do transexualismo. São Paulo: Nversos, 2011.

CZERMARK, Marcel. "Précisions sur la clinique du transsexualisme". In: FIERENS, Christian. Le discours psychanalytique: Une deuxième lecture d l'Etourdit de Lacan, n. 3, 1982. p. 16-22.

DUMARESC, Leila. "Ensaio (travesti) sobre a escuta (cisgênera)". Revista Periodicus, v. 1, n. 5, p. 121 131, maio-out. 2016.

FERNANDES, Maria Helena. Corpo. São Paulo: Casa do Psicólogo, 2003. (Coleção Clínica psicanalítica/dirigida por Flávio Carvalho Ferraz)

FOUCAULT, Michel. Em defesa da sociedade: curso no Collège de France (1975-1976). São Paulo: Martins Fontes, 1999.

FREUD, Sigmund. "Estudos sobre a histeria". In: FREUD, Sigmund. Edição Standard Brasileira das Obras Psicológicas Completas de Sigmund Freud. Rio de Janeiro: Imago, 2006a [1895].

FREUD, Sigmund. "Três ensaios sobre a teoria da sexualidade". In: FREUD, Sigmund. Edição Standard Brasileira das Obras Psicológicas Completas de Sigmund Freud. Rio de Janeiro: Imago, 2006b [1905].

FREUD, Sigmund. "O ego e o id". In: FREUD, Sigmund. Edição Standard Brasileira das Obras Psicológicas Completas de Sigmund Freud. Rio de Janeiro: Imago, 2006c [1923]. 
FREUD, Sigmund. "O mal-estar da civilização". In: FREUD, Sigmund. Edição Standard Brasileira das Obras Psicológicas Completas de Sigmund Freud. Rio de Janeiro: Imago, 2006d [1930].

GROSSI, Miriam Pillar. "A Revista Estudos Feministas faz 10 anos: uma breve história do feminismo no Brasil". Revista Estudos Feministas, Florianópolis, p. 211 , jan. 2004. Disponível em https:// periodicos.ufsc.br/index.php/ref/article/view/S0104-026X2004000300023/9519. Acesso em 20/12/ 2018. ISSN 1806-9584.

JORGE, Marco Antônio Coutinho; TRAVASSOS, Natália Pereira. Transexualidade: o corpo entre o sujeito e a ciência. Rio de Janeiro: Zahar, 2018.

JESUS, Jaqueline Gomes (Org.). Transfeminismo: teorias e práticas. 2. ed. Rio de Janeiro: Metanoia, 2015.

LACAN, Jacques. Seminário, Livro 18: de um discurso que não fosse semblante. Rio de Janeiro: Zahar, 2009.

LAGO, Mara C. de Souza. "A psicanálise nas ondas dos feminismos". Repositório Institucional UFSC, 2012. Disponível em https://repositorio.ufsc.br/handle/123456789/1350. Acesso em 02/01/2019.

LAQUEUR, Thomas. Inventando o sexo. Corpo e gênero dos gregos a Freud. Rio de Janeiro: Relume Dumará, 2001.

LEITE JR., Jorge. Nossos corpos também mudam: a invenção das categorias "travesti" e "transexual" no discurso científico. São Paulo: Annablume; FAPESP, 2011.

LUCON, Neto. "OMS irá retirar identidades trans e travestis do capítulo de transtornos mentais". Clipping LGBT, 2018. Disponível em http://www.nlucon.com/2018/05/oms-retira-identidades-transe-travesti.html. Acesso em 07/05/2018.

MARIANO, Silvana Aparecida. "O sujeito do feminismo e o pós-estruturalismo". Rev. Estud. Fem., Florianópolis, v. 13, n. 3, p. 483-505, 2005. Disponível em http://www.scielo.br/scielo.php?script=sci_ arttext\&pid=S0104-026X2005000300002\&lng=en\&nrm=iso. Acesso em 10/05/2018.

MILLOT, Catherine. Extrasexo: ensaio sobre o transexualismo. São Paulo: Escuta, 1992.

NARVAZ, Martha; KOLLER, Silvia. "Metodologias feministas e estudos de gênero: articulando pesquisa, clínica e política". Revista Psicologia em Estudo, Maringá, v. 11, n. 3, p. 647-654, set./ dez. 2006.

PINTO, Céli Regina. "Feminismo, história e poder". Rev. Sociol. Polít., Curitiba, v. 18, n. 36, p. 15-23, jun. 2010.

PISCITELLI, Adriana. "Gênero: a história de um conceito". In: ALMEIDA, Heloísa B.; SzWAKO, José E. (Orgs.). Diferenças, Igualdade. São Paulo: Berlendis \& Vertecchia, 2009. p. 116-149.

PORCHAT, Patricia. "A transexualidade hoje: questões para pensar o corpo e o gênero na psicanálise". Revista Brasileira de Psicanálise, São Paulo, v. 48, n. 4, p. 115-126, 2014 a.

PORCHAT, Patricia. "“Corpo e criatividade”. Revista EPOS, Rio de Janeiro, v. 5, n. 1, p. 112-130, $2014 \mathrm{~b}$.

PORCHAT, Patricia. "Gênero é um outro". In: MINELLA, Luzinete Simões; ASSIS, Gláucia de Oliveira; FUNCK, Susana Bornéo (Orgs.). Políticas e Fronteiras - Desafios Feministas. v. 2. Tubarão: Copiart, $2014 c$.

RINALDI, Doris. "O corpo estranho". Rev. Latinoam. Psicopat. Fund., São Paulo, v. 14, n. 3, p. 440-451, set. 2011.

RODOVALHO, Amara Moira. "O cis pelo trans". Revista Estudos Feministas, Florianópolis, v. 25, n. 1, p. 365-373, abr. 2017.

SAADEH, Alexandre. Transtorno de identidade sexual: um estudo psicopatológico de transexualismo masculino e feminino. 2004. Tese (Doutorado em Psiquiatria) - Faculdade de Medicina da Universidade de São Paulo, Universidade de São Paulo, São Paulo.

SAFOUAN, Moustapha. Estudos sobre o Édipo: introdução a uma teoria do sujeito. Rio de Janeiro: Zahar, 1979. 
SCOTT, Joan. "Gênero, uma categoria útil de análise histórica". Educação e Realidade, Porto Alegre, v. 20, n. 2, p. 71-99, jul./dez. 1995.

SPIZZIRRI, Giancarlo. "Aspectos genéticos relacionados ao transexualismo". Diagn Tratamento, São Paulo, v. 20, n. 2, p. 76-79, 2015.

STOLLER, Robert. A experiência transexual. Rio de Janeiro: Imago, 1982.

TEIXEIRA, Marina Caldas. "Mudar de sexo: uma prerrogativa transexualista". Psicologia em Revista, Belo Horizonte, v. 12, n. 19, p. 66-79, jun. 2006.

Patricia Porchat (patiporchat77@gmail.com) é psicanalista. Professora da Universidade Estadual Paulista (UNESP) de Bauru e do Programa de Pós-Graduação em Educação Sexual da UNESP de Araraquara. Possui Pós-Doutorado na Universidade Paris Diderot (2018/2019). Doutora em Psicologia Clínica pela Universidade de São Paulo. Membro do GT Psicologia e Estudos de Gênero da ANPEPP. Autora de livros e capítulos de livro sobre psicanálise, gênero e teoria queer.

Maria Caroline Ofsiany (mcarolof@gmail.com) é graduada em Psicologia pela UNESP, campus Bauru (2018). Foi membro do Laboratório Gênero Psicanálise e Sexualidade (GPS), da UNESP de Bauru. Atualmente é residente do Programa de Residência Multiprofissional em Saúde do Adulto e do Idoso da Faculdade de Medicina da UNESP, campus Botucatu. Áreas de estudo e interesse: saúde mental, corpo, sexualidade e psicanálise.

\section{COMO CITAR ESSE ARTIGO DE ACORDO COM AS NORMAS DA REVISTA}

PORCHAT, Patricia; OFSIANY, Maria Caroline. "Quem habita o corpo trans?". Revista Estudos Feministas, Florianópolis, v. 28, n. 1, e57698, 2020.

\section{CONTRIBUIÇÃO DE AUTORIA}

Patricia Porchat: Concepção da pesquisa, elaboração do manuscrito, redação e discussão de resultados.

Maria Caroline Ofsiany: Concepção da pesquisa, coleta de dados e análise de dados, elaboração do manuscrito, redação, discussão de resultados.

\section{FINANCIAMENTO}

FAPESP - Fundação de Amparo à Pesquisa do Estado de São Paulo. Bolsão de Iniciação Científica concedida à autora Maria Caroline Ofsiany, processo n. 2015/22361-0, no período de 01/05/2016 a 30/04/201 7. Título do projeto: $O$ estatuto do corpo na transexualidade: um diálogo entre o movimento transfeminista, a psicanálise e o discurso médico.

CONSENTIMENTO DE USO DE IMAGEM

Não se aplica.

APROVAÇÃO DE COMITÊ DE ÉTICA EM PESQUISA

Não se aplica.

\section{CONFLITO DE INTERESSES}

Não se aplica.

LICENÇA DE USO

Este artigo está licenciado sob a Licença Creative Commons CC-BY Internacional. Com essa licença você pode compartilhar, adaptar, criar para qualquer fim, desde que atribua a autoria da obra.

\section{HISTÓRICO}

Recebido em 14/06/2018

Reapresentado em 15/04/2019

Aprovado em 24/05/2019 